\title{
On withholding nutrition and hydration in the terminally ill: has palliative medicine gone too far?
}

\author{
Gillian M Craig Consultant Geriatrician, Northampton
}

\section{Author's abstract}

This paper explores ethical issues relating to the management of patients who are terminally ill and unable to maintain their own nutrition and hydration. $A$ policy of sedation without hydration or nutrition is used in palliative medicine under certain circumstances. The author argues that this policy is dangerous, medically, ethically and legally, and can be disturbing for relatives. The role of the family in management is discussed.

This issue requires wide debate by the public and the profession.

\section{Introduction}

From time to time in the professional life of a doctor incidents occur which cause one to stop and think hard. There are times when two doctors, each with the best interests of the patient at heart, would treat in diametrically opposite ways. There are widely divergent opinions on what is correct and morally acceptable when it comes to the management of patients who are, or appear to be, terminally ill and unable to maintain their own nutrition and hydration. This inability to eat and drink may be a consequence of the illness or of the treatment, for example heavy sedation. Differences in opinion about management may be voiced by relatives, by nurses and by doctors who may or may not be directly or professionally involved in the care of the patient. Particularly difficult management problems may arise if the dissenting relative is a nurse, doctor or paramedic, and great care must be taken to ensure that his or her views are taken into account and discussed openly, and that the management adopted is acceptable to all parties, if this is humanly and legally possible.

Ethical dilemmas in the field of hydration and nutrition cover a wide spectrum, from dehydration due to dysphagia of various aetiologies, through terminal cancer with intestinal obstruction, to the

\section{Key words}

Nutrition; hydration; sedation; terminally ill; ethics; euthanasia. persistent vegetative state, terminal Alzheimer's disease patients who are unable to eat, and patients with anorexia nervosa or elderly depressives who deliberately refuse nourishment to the point of selfannihilation. The main issue highlighted by this paper is the use of sedation without hydration or nourishment in the terminally ill. This raises ethical issues which require debate by the profession and the public.

\section{The need for an open mind about intravenous hydration in terminal care}

Palliative medicine is a relatively new and growing specialty and the hospice movement is held in high esteem by the public. Some doctors, however, have reservations. There are dangers in grouping patients labelled 'terminal' in institutions, because diagnoses can be wrong (1). There is a risk that if all the staff in an institution are orientated towards death and dying and non-intervention, treatable illness may be overlooked. Not everyone who is referred for terminal care proves to be terminally ill, and no physician should accept such a diagnosis without reviewing the evidence personally.

Certain policies that are practised in palliative medicine would be dangerous if applied without due care and thought. In particular the view that in the terminal phase of disease 'no form of artificial hydration or alimentation is undertaken, all measures not required for comfort are withdrawn, and no treatment-related toxicity is acceptable' (2). It is not uncommon for the elderly to be admitted to hospital in a seriously dehydrated condition, looking terminally ill. A treatment-orientated physician will rehydrate these patients energetically, often with dramatic results, in order to buy time in which to assess the situation carefully. A therapeutically inactive doctor would lose many patients for the sake of avoiding a drip. Two examples from my personal experience will illustrate this point.

\section{Case 1}

An elderly man was sent to hospital for terminal care with a diagnosis of carcinoma of the pancreas. $\mathrm{He}$ 
had indeed had a stent inserted at another hospital to relieve bilary obstruction due to tumour. However, his 'terminal' illness was due to a small stroke and uncontrolled diabetes mellitus. He recovered with insulin and intravenous rehydration and lived happily for several weeks more.

\section{Case 2}

An elderly man was admitted for terminal care but the geriatrician felt the diagnosis of cancer was not well established. The main problem was severe dehydration with ischaemic feet and severe pressure sores on the heels. With intravenous rehydration and intensive nursing he recovered and went home for 18 months.

It is important for the public to realise that most patients with terminal illness can continue to eat and drink as and when they wish. Only in the last days may they be too weak or tired to bother, in which case the lack of food and drink will not contribute to death. If dehydration develops under these circumstances it is a natural consequence of irreversible disease, and artificial hydration would not be appropriate.

\section{The use of sedation}

There are times in the care of the dying 'when it is necessary to use benzodiazepines, phenothiazines and barbiturates to sedate a patient in order to relieve intolerable distress where dying is complicated by an agitated delirium or tracheal obstruction' (3). In skilled hands no person should die in pain, whatever the cause of the illness. As a last resort some people advocate use of high-dose analgesia and induction of sleep with continuous intravenous midazolam (4). Whatever the underlying pathology 'the cardinal ethical principle remains that the treatment goal must be achieved with the least risk to the patient's life' (3). I would add - and in a manner that is acceptable to the patient's closest relatives.

Having decided that sedation is needed, the doctor must try to find a drug regime that relieves distress but does not prevent the patient from taking fluid and nourishment, does not prevent verbal communication with friends and relatives, and does not lead to toxic side-effects, or expedite death. Unfortunately currently available therapeutic options are not ideal in all these respects. Even light sedation can cause drowsiness that may prevent a person from taking enough fluid to maintain hydration. Heavy sedation may render an alert person incapable of swallowing within minutes, depending on the drug regime used.

If death is imminent few people would feel it essential to put up a drip but ethical problems arise if sedation is continued for more than one or two days, without hydration, as the patient will become dehydrated. Dehydration can result in circulatory collapse, renal failure, anuria and death. I do not think it is morally acceptable to leave a sedated patient for long without hydration. Others would $\frac{}{9}$ dissent from this view using words such as? 'meddlesome' and 'unethical' if intravenous fluids 을 are suggested under such circumstances. However, in my opinion, if it is not possible to reduce sedation $\mathbb{\otimes}$ to a level that enables the patient to drink, the question of hydration must be addressed to everyone's satisfaction.

Particular problems may arise if the patient has a $\overrightarrow{\vec{\omega}}$ primary mental disorder such as chronic $\stackrel{\sigma}{\omega}$ schizophrenia or depression. In such people the $\overline{\bar{\nabla}}$ stress of the physical illness may make the mental state worse. Great skill may be needed to distinguish a potentially treatable psychotic reaction from an $\omega$ untreatable, terminal agitated delirium. In cases of $\vec{\omega}$ difficulty expert psychiatric help should be obtained $\mathrm{O}$ as the distinction may be vital. If the diagnosis is a psychotic reaction, hydration must be maintained $\vec{\omega}$ and the patient observed in the hope that sedation $\mathbb{D}$ can be reduced. If the diagnosis is a terminal $\underset{\mathbb{D}}{ }$ agitated delirium, those with experience advise $\frac{3}{\sigma}$ against reducing sedation, and argue against giving $\mathbb{\mathscr { D }}$ intravenous fluids as this would prolong dying.

To take a decision to sedate a person, withoof hydration, until he/she dies is a very dangerous. policy medically, ethically and legally. No doctors judgement is infallible when it comes to predicting how close a patient is to death. To say that it is a matter of days, and to treat by this method, is to $\stackrel{\circ}{\mathbb{D}}$ make the prediction self-fulfilling. I know of a patient who died after at least seven days of sedation $\overline{\vec{O}}$ without hydration - how much longer would he have survived with hydration? Diagnostic errors can also occur. A reversible psychosis or confusional state can be mistaken for terminal delirium, aspiration pneumonia for tracheal obstruction, obstruction due to faecal impaction for something more sinister, and so on. The only way to ensure that life will not be shortened is to maintain hydration during sedation in all cases where inability to eat and drink is a direct consequence of sedation, unless the relatives request no further intervention, or the patient has made his/her wishes known to this effect. If naturally or artificially administered hydration and nutrition is $\sigma$ withheld, the responsible medical staff must face the $N$ fact that prolonged sedation without hydration or $N$ nutrition will end in death, whatever the underlying $O$ pathology. Even a fit Bedu tribesman riding in the desert in cool weather, can only survive for seven days without food or water (5).

\section{The legal question}

The Institute of Medical Ethics working party on the $\stackrel{?}{\mathbb{P}}$ ethics of prolonging life and assisting death has $\frac{\varrho}{\sigma}$ argued the case for withdrawing food and water from patients in a persistent vegetative state (6). Such 
patients are unaware of their surroundings as a result of severe brain damage. Recent reports indicate that 'persistent' does not necessarily mean 'permanent' (7) and it is essential to ensure that the prognosis is hopeless before considering withdrawing treatment (8).

A key issue in English law in such patients has been 'whether artificial feeding counts as medical treatment - which can lawfully be discontinued if the patient is receiving no benefit - or is simply the means of sustaining life, which if withdrawn could lay a doctor open to a charge of murder' (8). This argument is largely semantic since in patients with a persistent vegetative state this treatment sustains life. The key issue surely is whether it benefits the patient to be alive rather than dead. Those who advocate withdrawing food and water from these patients have been warned by medical defence organisations that such a policy may result in a charge of manslaughter by neglect (9). This risk has been reduced but not eliminated by the Bland case ruling (10) which has clarified the legal position in England and Wales. The legal position in Scotland remains unclear but is being actively reviewed by the Lord Advocate following the judgement in the Bland case.

\section{The case of Airedale NHS Trust $v$ Bland}

In the final judgement or declaratory statement made in the House of Lords in February 1993, it was ruled that the responsible attending physicians could lawfully discontinue all life-sustaining treatment and medical supportive measures designed to keep the patient (Mr Bland) alive in his persistent vegetative state, including the termination of ventilation, nutrition and hydration by artificial means (10). In coming to this judgement, the Law Lords accepted as responsible medical opinion, a paper prepared by the British Medical Association (BMA) medical ethics committee (11). Referring to this the judges highlighted four safeguards which should be observed before discontinuing life support in a patient with a persistent vegetative state - namely, 1 . Every effort should be made at rehabilitation for at least six months after injury; 2. The diagnosis of irreversible persistent vegetative state should not be considered confirmed until at least 12 months after injury; 3 . The diagnosis should be agreed by at least two other independent doctors, and 4 . Generally the wishes of the patient's immediate family should be given great weight.

Lord Goff pointed out that to discontinue artificial feeding might be categorised as an omission, which if deemed to constitute a breach of duty to the patient is unlawful (10). However, in the case of $\mathrm{Mr}$ Bland, he argued that the patient was incapable of swallowing and therefore of eating and drinking in the normal sense of these words. Artificial feeding via a nasogastric tube was therefore a form of life support, and could be discontinued if treatment was futile and no longer in the best interests of the patient.

It must be emphasised that the case of Airedale NHS Trust $\mathrm{v}$ Bland does not give doctors freedom to withdraw treatment from all patients in a persistent vegetative state. For the foreseeable future doctors in England and Wales must apply to the family division of the High Court for a declaration in each case as to the legality of any proposed discontinuance of life support, where there is no valid consent on the part of the patient. There has not been a rush of applications to date. Moreover a civil court ruling is no guarantee against subsequent prosecution in a criminal court, since a declaration as to the lawfulness or otherwise of future conduct is 'no bar to a criminal prosecution, no matter the authority of the court which grants it' (12).

The judgement regarding hydration and nutrition in the Bland case was clearly swayed by the patient's irreversible brain damage, although the law as to killing is unaffected by the victim's mental state (13). It would be extremely dangerous to extrapolate the legal decision made in this case to other clinical situations. The legality or otherwise of withholding hydration and nutrition from the dying has not been tested in the courts in the United Kingdom (13).

Despite the differences in mental state, pathology and life expectation between a terminally ill sedated patient and one with a persistent vegetative state, the key issues are similar. Are you, by withholding fluid and nourishment, withholding the means of sustaining life? In short are you killing the patient? The answer I fear in some cases could be YES. In some terminally ill patients, especially those who are rendered unable to swallow by heavy sedation, failure to hydrate and nourish artificially could be judged an unlawful omission. The question of intent is important and the principle of double effect, and other medico-legal issues are relevant (13). However, doctors who deliberately speed death could face the prospect of life imprisonment (13). Clearly the legality of prolonged sedation without hydration is highly debatable yet this treatment is regarded as ethical and compassionate by senior and respected specialists in palliative medicine. If a dying patient is treated in this way there may be reasonable grounds for doubt as to whether the patient died of the treatment or the disease. It is our duty and our privilege as doctors to sustain life, not to shorten it. Euthanasia must remain illegal, and practices that seem tantamount to euthanasia must be exposed.

\section{The risk of inappropriate sedation}

Clearly a policy of sedation without hydration or nutrition in terminal care is a drastic solution to a difficult problem. Those who take such action no doubt do so thinking that they have the patient's best 
interests at heart. They may also be influenced by subconscious fears. As Main said: 'Perhaps many of the desperate treatments in medicine can be justified by expediency, but history has an awkward habit of judging some as fashions, more helpful to the therapist than the patient. Patients tend to be sedated when the carers have reached the limit of their resources, and are no longer able to stand the patient's problems without anxiety, impatience, guilt, anger or despair. A sedative will alter the situation and produce a patient who if not dead, is at least quiet' (14). The case of the Winchester rheumatologist who was convicted of attempted murder demonstrates what can happen when doctor and patient reach the end of their tether $(15,16)$.

\section{The importance of comfort}

The guiding principle in the care of the dying is that 'everything in the terminal phase of an irreversible illness should be clearly decided on the basis of whether it will make the patient more comfortable and whether it will honour his/her wishes' (17). 'Comfort' is a state of conscious physical and mental well-being. It is debatable therefore whether the word can be applied to a heavily sedated, dehydrated patient. However, most would agree that it is preferable to be comfortable and conscious or semiconscious without pain, than uncomfortable, distraught and fully awake.

The therapeutic ideal would be to have a patient who is calm, clear-headed and pain-free. Unfortunately there are times when this cannot be achieved with the drugs at our disposal.

The consensus in the hospice movement seems to be that rehydration and intravenous fluids are inappropriate in terminal care $(2,18,19)$. Dehydration is even considered to be beneficial in patients with incontinence (18)! This is a weak argument to justify withholding intravenous fluids. Therapeutic anuria may be the ultimate cure for incontinence but the side-effect is death. Those who have coped with incontinence without a catheter in the past can be nursed without a catheter to the end, if that is their wish. Rehydration should not influence this aspect of care. Hospice staff also argue that a drip makes it more difficult to turn a dying patient in bed, yet they are happy to give analgesics by subcutaneous infusion when necessary, and occasionally use a drip in patients with hypercalcaemia. To those of us who use drips frequently on acute medical, surgical and geriatric wards, these arguments do not carry much weight. Setting up a drip or a subcutaneous infusion is a simple and straightforward procedure that rarely causes the patient discomfort or distress. Many dehydrated patients look and feel a lot better when they are rehydrated. If the staff in hospices used drips more, they would not have to find so many reasons for avoiding them.

\section{The question of thirst}

If hydration and nutrition are withheld, the attendant staff must be sensitive to the effect this may have on the family and friends (17). Some say that a patient should be comatose, so as not to experience thirst, before it is morally acceptable to withhold or withdraw intravenous fluids (20). It is widely assumed that a terminally ill patient is not $\mathbb{\mathbb { D }}$ troubled by hunger or thirst but this is difficult to substantiate as few people return from the grave to complain. Thirst may or may not bother the patient. Concern about thirst undoubtedly bothers relatives. They will long to give their loved one a drink. They may sit by the bed furtively drinking cups of tea, taking care to make no sound lest the clink of china is torture to the patient. Anyone who has starved for hours before an anaesthetic will sympathise with dying patients who seem to thirst and starve for days. Nurses are taught that moistening the patient's 0 mouth with a damp sponge is all that is necessary to prevent thirst. Relatives may not be convinced. It $\rho$ may well be that sedation relieves the sensation of $\frac{\mathbb{D}}{O}$ hunger and thirst. If there is evidence to this effect it would be helpful for the relatives of dying patients to be told about it.

\section{The role of the family}

It has been said that the family must request further medical procedures before treatment can be withheld and that the previously expressed wishes of the patient or current family must predominate over those of staff (20). Staff who believe strongly that intravenous fluids are inappropriate should not impose their views on knowledgeable or distressed relatives who request that a dying patient be given intravenous fluids to prevent dehydration or thirst. To overrule such a request is, in my view, ethically wrong. The only proviso would be if the patient had, when compos mentis, specifically said that he/she did not want a drip under any circumstances.

No relatives should be forced to watch a loved one die while medical staff insist on withholding hydration. This has happened to my knowledge. Such an experience is deeply disturbing and could haunt a person forever. Is all this agony worth it for the sake of avoiding a drip? I think not.

The converse also applies. There will be occasions $N$ when the medical staff who are professionally involved would like to use a drip, but a knowledge- 0 able relative requests no intervention. In this situation, the medical team will need to make a carefully balanced judgement as to whether inter- $\stackrel{\infty}{\rightarrow}$ vention is essential or not. If the scales are not heavily weighted in favour of intervention the wise $\overline{0}$ doctor will compromise and stand back in the $\mathbb{\mathbb { D }}$ interests of the peace of mind of the relative.

A doctor cannot be obliged to act contrary to his or $\frac{a}{\sigma}$ her own conscience but equally doctors should bear in mind that relatives also have consciences, and 
should not be forced to accept for their loved ones treatment that they consider to be unethical. It is inevitable that terminally ill patients will die and that their relatives will be sad. Care must be taken to ensure that the burden of bereavement is not loaded heavily by distress about patient management in the terminal phase. In the care of the dying, both patients and their relatives must be treated with compassion.

\section{Final comments}

The question of hydration and nutrition in terminal care is one that generates strong views. It is probably inevitable that sooner or later those working in the field of palliative medicine will meet colleagues working in different fields of medicine who are used to adopting a more active approach to management. Those who don't believe in using intravenous fluids will encounter those who do. Faced with this situation it is essential that both parties sit down together to discuss the issues. They must reach a compromise that takes into account the expressed or probable wishes of the patient concerned and the views of the closest relatives. No one individual has right entirely on his/her side. The ethically correct solution may prove to be somewhere in the middle, and it must be found.

Where opinions differ on the management of an individual case, further discussion may throw light on the situation, firmly held opinions may prove to be wrong, diagnoses may need to be revised and factors that had not been considered before may soften entrenched attitudes. If the issue is the futility or otherwise of intervention, or doubt about the patient's views or best interest, there may be room for manoeuvre in any given situation. The underlying reasons for sedation and the cause of the patient's inability to eat and drink are obviously of critical importance. What is essential in the final analysis is that all parties should feel comfortable with the clinical management strategy adopted. If this is not the case the strategy is probably not ethically sound. Somewhere between the poles of opposing opinion there must be some morally acceptable common ground. If after further discussion a mutually acceptable management policy cannot be agreed, it is no solution to the dilemma for a hospice team to tell the relatives to take the dying patient elsewhere. Where for example can you take a dying man, in the middle of winter, in an ambulance strike? However strong your ethical position, it is unacceptable to seek to silence dissent in this way. Where time permits, a second consultant opinion should be sought, or help from some other appropriate independent source.

As Rabbi Lionel Blue said recently of theology: 'Even more important than your views is the kindness with which you hold them, and the courtesy with which you treat those who oppose you'. The same could be said of the issues explored in this paper. People who hold strong views in this difficult and emotive area of palliative medicine should hold them kindly and with sensitivity. At the end of the day there should not be the slightest grounds for suspicion that death was due to anything but the disease. Unless this can be guaranteed, the public's faith in doctors in general, and in the hospice movement in particular, will be ill founded.

Gillian Craig, MD, FRCP, is a retired Consultant Geriatrician.

\section{References}

(1) Kamisar Y. In: Downing A, ed. Euthanasia and the right to death. London: Peter Owen, 1969: 100-101.

(2) Ashby M, Stoffell B. Therapeutic ratio and defined phases: proposal of ethical framework for palliative care. British medical journal 1991; 302: 1322-1324.

(3) Twycross R G. Assisted death: a reply. Lancet 1990; 336: 796-798.

(4) Tapsfield W, Amis P [letter]. British medical journal 1992; 305: 951.

(5) Thesiger W. Arabian sands. London: Readers' Union, Longmans, Green \& Co, 1960: 87.

(6) Institute of Medical Ethics working party on the ethics of prolonging life and assisting death. Withdrawal of life support from patients in a persistent vegetative state. Lancet 1991; 337: 96-98.

(7) Andrews K. Managing the persistent vegetative state. British medical journal 1992; 305: 486-487.

(8) Dyer C. BMA examines the persistent vegetative state. British medical journal 1992; 305: 853-854.

(9) Baron J H [letter]. Lancet 1991; 337: 639.

(10) House of Lords. Law Report. Withdrawal of medical treatment from hopeless case not unlawful. The Times 1993 Feb 5: 8

(11) Medical ethics committee of the British Medical Association. Discussion paper on treatment of patients in persistent vegetative state. London: BMA, 1992.

(12) See reference (10): Viscount Dilhorne in Imperial Tobacco Ltd v Attorney General 1981. AC 718741 Quoted by Lord Goff.

(13) Mason J K, McCall Smith R A. Law and medical ethics [3rd ed]. London: Butterworths, 1991: 317-343.

(14) Main T F. The ailment. British journal of medical psychology 1957; 30: 129-145.

(15) Dyer C. Rheumatologist convicted of attempted murder. British medical journal 1992; 305: 731.

(16) Illidge $\mathrm{T} M$, Kirkham S R [letter]. British medical journal 1992; 305: 1225.

(17) Wanzer S H, Adelstein S J, Cranford R E et al. The physician's responsibility toward hopelessly ill patients. New England journal of medicine 1984; 310: 955-959.

(18) Sykes N. The last 48 hours of life: caring for patient, family and doctor. Geriatric medicine 1990;20, 9: 22-24.

(19) Belcher N G. Pulling out the drip: an ethical decision in the terminally ill. Geriatric medicine 1990;20, 6: 22-23.

(20) Micetich K C, Steinecker P H, Thomasma D C et al. Are intravenous fluids morally required for a dying patient? Archives of internal medicine 1983; 143: 975-978. 